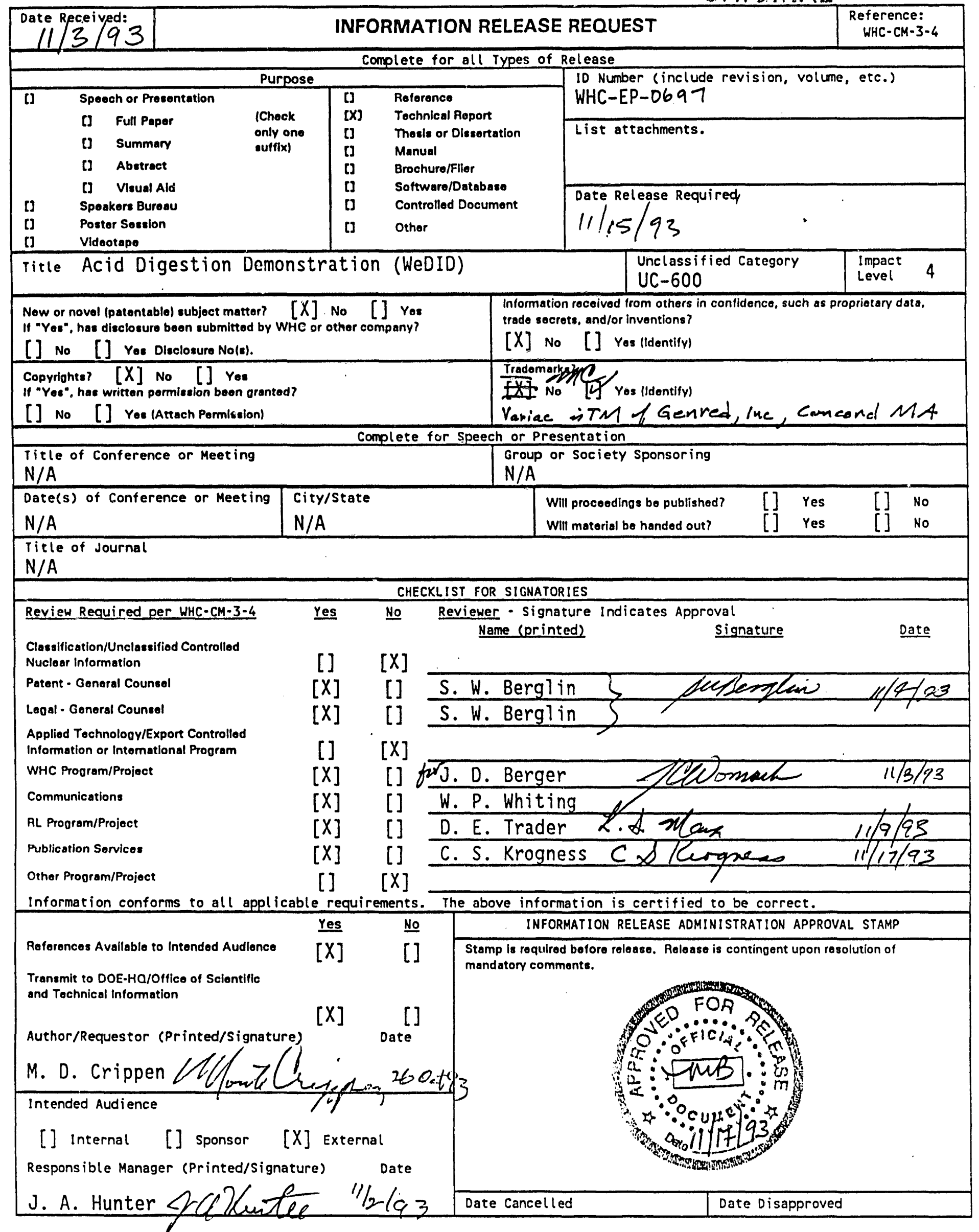




\title{
Acid Digestion Demonstration (WeDID)
}

\author{
M. D. Crippen
}

Date Published

November 1993

Prepared for the U.S. Department of Energy Office of Environmental Restoration and Waste Management

\section{Q2 Westinghouse Hanford Company Richland, Washington 99352 \\ Hanford Operations and Engineering Contractor for the \\ U.S. Department of Energy under Contract DE-AC06-87RL10930}

Approved for Public Release

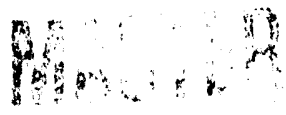


Document Title: Acid Digestion Demonstration (WeDID) Office of Technology Development

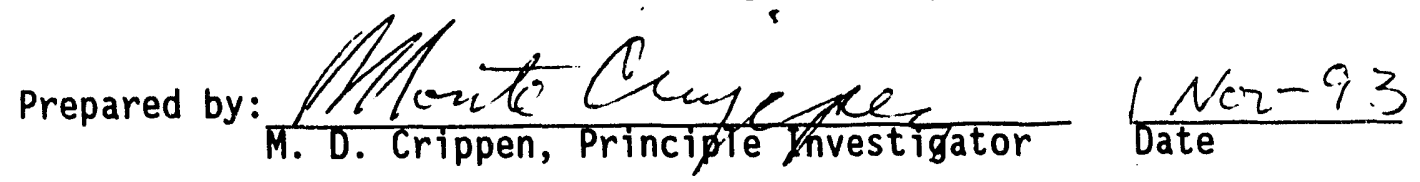
Reviewed by: $\frac{\text { Aflecente }}{\text { J. Hunter, }} \frac{11 / 2 / 93}{\text { Date }}$ Approved by: $11 / 3 / 53$ Office of Technology Integration

Approved by: D. E. Trader, Technical Program officer U.S. Department of Energy, Richland Operations office 


\section{WHC-EP-0697}

\section{CONTENTS}

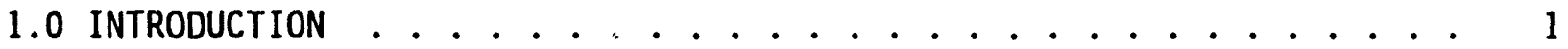

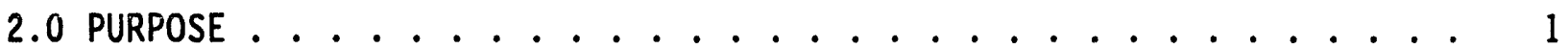

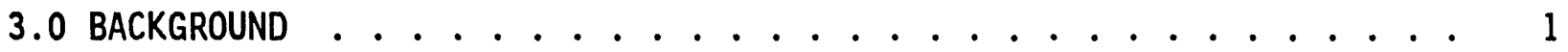

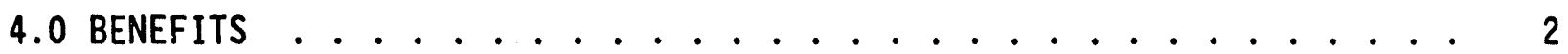

5.0 CRITERIA FOR SUCCESS ...................... 2

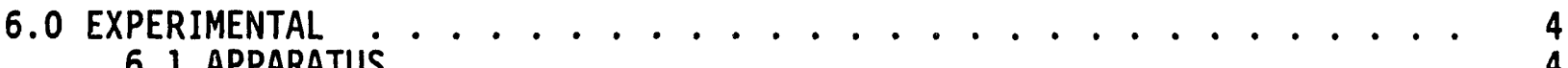

6.1 APPARATUS ........................ 4

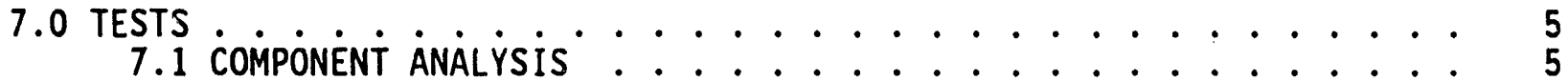

7.2 FIRST TEST . . . . . . . . . . . . . . . . 5

7.3 SECOND TEST ...................... 6

7.4 THIRD TEST ....................... 6

7.5 FOURTH TEST . . . . . . . . . . . . . . . . . . . 7

7.6 SOLIDIFICATION . . . . . . . . . . . . . . . . . . . 7

8.0 SUMMARY ........................... . . 7 
WHC-EP-0697

\section{LIST OF FIGURES}

1. Acid Digestion Flow Diagram. . . . . . . . . . . 3 
WHC-EP-0697

\section{LIST OF TERMS}

EPA

PCBS

U.S. Environmental Protection Agency

RADTU polychlorinated biphenyls

Sandia

TCLP

Radioactive Acid Degestion Test Unit

WeDID

Sandia National Laboratory

Toxic Leach Characteristic Procedure

WHC

Weapons Destruction Integrated Demonstration

Westinghouse Hanford Company 
ACID DIGESTION REPORT

by

Monte Crippen

\subsection{INTRODUCTION}

Acid digestion process development began at the Hanford Site in 1972 with a beaker of laboratory acid and progressed through 1aboratory and pilotscale development culminating in the Radioactive Acid Digestion Test Unit (RADTU). The RADTU was operational from 1977 through 1982 and processed over $5,000 \mathrm{~kg}$ of synthetic and combustible waste forms from Hanford Site operations. It routinely reacted plastics, wood, paper, cloth, ion-exchange resins, metals, and solvents. Because of funding limitations, RADTU was placed in ready standby in 1982 .

Operation of RADTU routinely gave volume reductions of 100:1 for most plastics and other combustibles. The residue was inert and was disposed of both as generated and after application of other immobilization techniques, such as calcination, addition to glass, and cement addition. The system was designed to accommodate offgas surges from highly reactive nitrated organics and successfully demonstrated that capability. The system was designed and operated under very stringent safety standards.

The Weapons Destruction Integrated Demonstration (WeDID) program required a technology that could dispose of an assortment of weapon components, such as complex electronics, neutron generators, thermal batteries, plastics, cases, cables, and others. A program objective was to recycle and reuse materials wherever possible, but many unique components would need to be rendered inactive, inert, and suitable for disposal under current environmental laws. Acid digestion technology was a key candidate for treating many of the above components; it provided accepted technology for treatment of chemicals and elements that have posed disposal difficulties designated by the U.S. Environmental Protection Agency (EPA).

\subsection{PURPOSE}

The purpose of this effort was to demonstrate the value of acid digestion as a technology to deactivate, reduce volume, and process certain electronic components to arrive at a final waste form suitable for disposal under current EPA regulations.

\subsection{BACKGROUND}

The acid digestion process is a chemical oxidation reaction that takes place in a liquid medium at relatively low temperatures (below $250^{\circ} \mathrm{C}$ ). Sulfuric and nitric acids are used to carbonize and oxidize organic waste 
materials to carbon dioxide and water; thus, plastics and polychlorinated biphenyls (PCBs) are destroyed. Circuit boards potted in organic resins would be reduced to an inactive ash residue of inert material. Thermal batteries and firing squibs would be deactivated and rendered inert. Land-banned metallic elements (e.g., lead, chromium, cadmium) would be converted to sulfates and oxides. It should be noted that acid digestion of some materials, such as metals, will actually give a volume and weight increase; however, the digested compounds may be inert or benign relative to the original material.

Figure 1 is an overall flow diagram of the integrated process. It contains all the major elements that would be required for a full-scale system. Although the laboratory system was small, it did have all of the elements or operations shown.

This task provided equipment to demonstrate the disposal of kilogram quantities of typical potted electronics, circuit boards, and related parts, such as connectors. A demonstration phase was conducted to determine volume and weight reduction efficiencies as well as operating parameters, such as temperature, times, and chemical consumption.

Selected specimens were analyzed by Westinghouse Hanford Company (WHC) to determine the leachability of designated elements, such as lead, chromium, and cadmium. Further fixation techniques were demonstrated as appropriate for final disposal of these forms.

Disposal of most electronic components was complicated by the presence of certain metal constituents, which are potential environmental and health risks. To complicate the problem, many of these constituents are in combinations that obviate many conventional treatment technologies. Treatment of these waste materials via acid digestion will transform these materials to an inert state and reduce the volume required for disposal.

\subsection{BENEFITS}

The Acid Digestion Demonstration provides a baseline capability for using the technology as a treatment process for potted electronics before disposal. The size reduction would increase the storage volume efficiency and allow for further analysis of potential problem elements, such as lead, chromium, and cadmium. An acid digestion system would provide a closed system to protect workers from hazardous materials during disposal operations, as well as a disposal form that minimizes long-term environmental impact. The past performance and success of the RADTU with its wide variety of tested materials was an asset to the implementation of this technology for potted electronics treatment.

\section{0 CRITERIA FOR SUCCESS}

Results from the Acid Digestion Demonstration were critical to the success of the WeDID Project. Key results were the destruction of organics and PCBs to better than $99 \%$ and the immobilization of metals, such as lead and cadmium, to accepted leachability standards. 


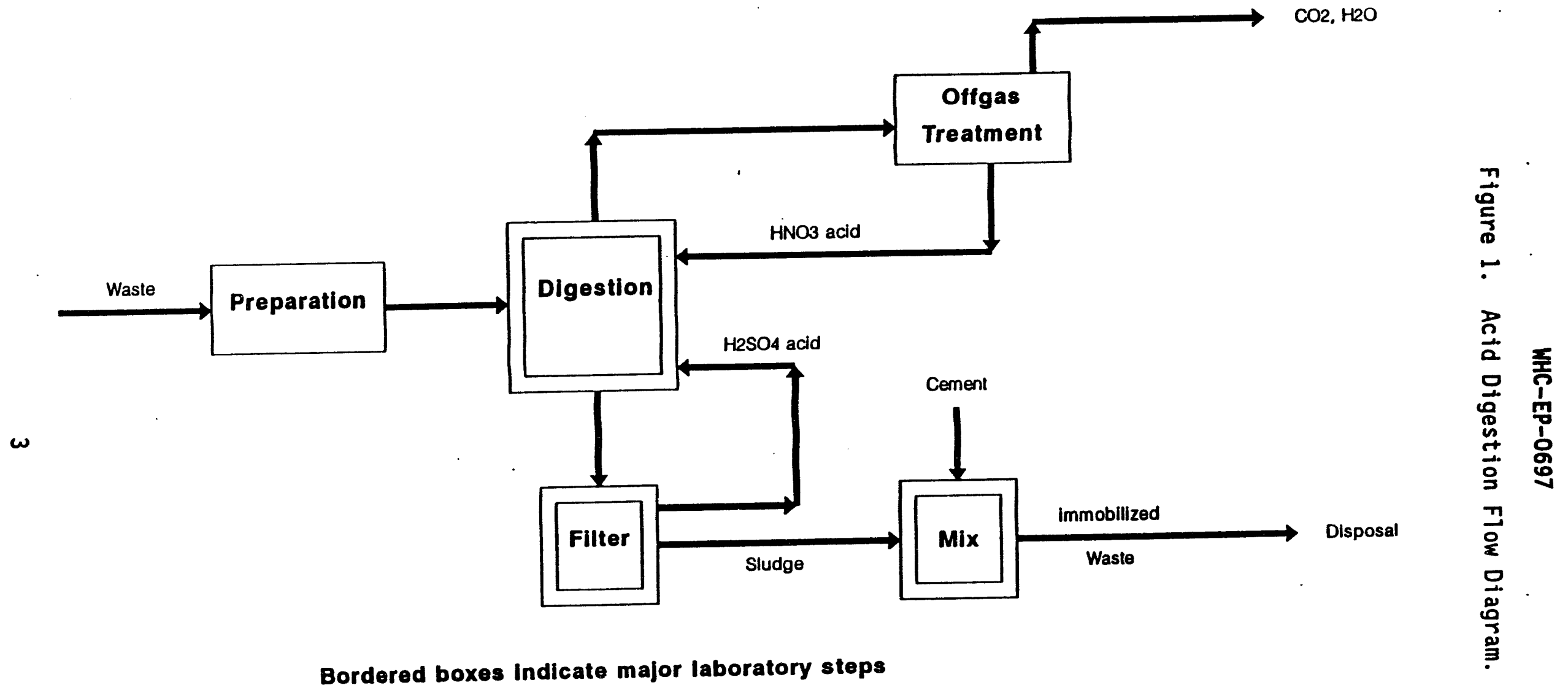

Bordered boxes indicate major laboratory steps 


\section{WHC-EP-0697}

Various parts of the program were accomplished as follows:

- Digestion of a nonweapons circuit board to demonstrate the capability of acid digestion technology to deactivate, size reduce, and process certain electronic components

- Purchase and assembly of glassware, pumps, auxiliary equipment, and monitoring instruments required for day to day operation

- Digestion of several additional, actual weapon components to provide further demonstration quantities for review, analysis, and environmental testing

- Using digestion residues, demonstrate a final disposal product using cementus adders, calcination, or other suitable means

- Prepare a final report of all activities and accomplishments of the Acid Digestion Demonstration, including documentation of all runs, laboratory tests, fixation tests, environmental tests, and other efforts expended on behalf of the project.

\subsection{EXPERIMENTAL}

\subsection{APPARATUS}

The apparatus consisted of a $2-L$ spherical flask nested in a $500-W$ heating mantel. The mantel was controlled through a Variac unit and used manual feedback for temperature control. Openings in the top of the flask provided for temperature measurement, offgas venting, and addition of nitric acid via a subsurface sparge tube. The nitric acid was added from a caliorated reservoir through a peristaltic pump, which could control the addition rate over a range of flow rates. The offgas passed through a partial reflux condenser that returned nearly all of the acid values and water back to the reaction flask. A secondary condenser was used to minimize vapor emissions to the hood environment.

Operation of the reaction flask was straightforward and stable; it did not exhibit unexpected surges or control problems. After initial heatup and reaction of the waste, the required heat input was constant. The final stages of reaction required an increase in heat energy to maintain the proper temperature.

A typical test was conducted as follows: The test material underwent size reduction via grinding or hammer mill to fragments less than $1 / 4$ in. as a maximum dimension. This is not required for the chemistry of the process but does facilitate handling and measuring for a small laboratory system. Up to $200 \mathrm{~g}$ of the solid was added at one time to $1 \mathrm{~L}$ of cold sulfuric acid (usually recycled from the previous run) in the reaction flask. There is little or no sign of any reaction between the acid and solid under these conditions. Final assembly of the reaction flask was completed, and it was heated at about $200{ }^{\circ} \mathrm{C} / \mathrm{h}$ up to 230 to $240{ }^{\circ} \mathrm{C}$. Above $100{ }^{\circ} \mathrm{C}$ there is ample evidence of

\footnotetext{
${ }^{1}$ Variac is a trademark of Genred, Incorporated.
} 
dehydration of the solids, resulting in the formation of elemental carbon and sulfur dioxide. Upon reacting, reaction temperature?? a flow of nitric acid was started, and the carbon was reacted to give carbon dioxide, water, and $\mathrm{NO}_{\mathrm{x}}$. After a short period, the nitric flow was decreased as the carbon was consumed until the reaction media remained "white." This completed the digestion of the sample.

After overnight cooling of the reacted material, it was filtered and dried. This presented some difficulties because the glass fibre and mineral fillers that are typical of circuit boards now form a material that retains liquids. Post drying examination showed little or no metallic or other fragments that were identifiable. At this point the processing was considered complete, and the residues were packaged for shipment to Sandia National Laboratory (Sandia) or other analysis or treatment at the Hanford Site.

\subsection{TESTS}

\subsection{COMPONENT ANALYSIS}

Sandia National Laboratory supplied the following elemental analys is on one of the early test components. It is oriented toward elements and not compounds.

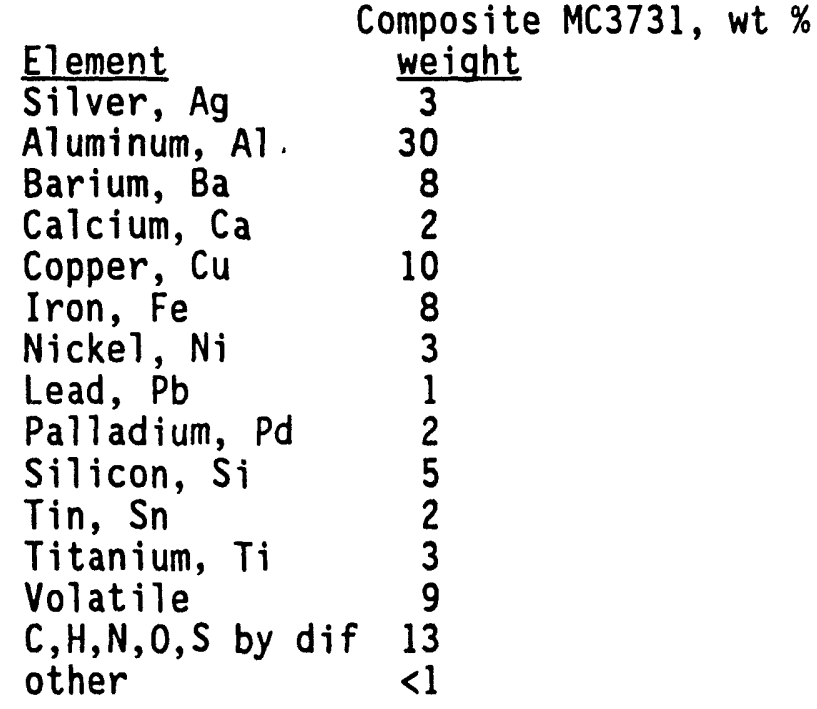

\subsection{FIRST TEST}

An initial demonstration of acid digestion on a surrogate circuit board was conducted from February 27 through March 4, 1992.

The circuit board was originally 6 in. $x 4$ in. $x 0.5$ in. and was sectioned into several pieces and inserted into the reaction vessel through a $0.75-i n$. porthole. The volume of material inserted into the vessel was $66 \mathrm{~g}$. The material collected following the drying $c^{c}$ the acid-sludge mixture weighed $63.54 \mathrm{~g}$. This material was returned to the sponsor in three containers for analysis. The bulk of the dried circuit board material was placed in two 
larger containers. The powder in the smaller container was washed with water from the inner walls of the reaction vessel and subsequently dried in an inert atmosphere furnace.

\subsection{SECOND TEST}

The demonstration of acid digestion on the first actual weapon component was completed in June 1992.

Upon receipt from Sandia, the crushed weapon component was loaded into the processing vessel, although some sectioning of larger pieces was required. The total weight of material loaded into the vessel was $396 \mathrm{~g}$. The residue collected following the drying of the acid-sludge mixture weighed $1,556 \mathrm{~g}$. This material was shipped to Sandia for further analyses.

One liter of sulfuric acid was heated to operating temperature in $2.5 \mathrm{~h}$ and the sample added to the liquid. After 40 minutes the addition of nitric acid was started and $600 \mathrm{mls}$ ??mL was used over $12 / 3$ hours. Drying was conducted daily for 10 days and recovered $1.05 \mathrm{~L}$ of acid condensate. The $2.2 \mathrm{~kg}$ of "mud" from this was finally reduced to $1.6 \mathrm{~kg}$ by heating it on a hot plate.

\subsection{THIRD TEST}

The second and third weapon?? components were treated via acid digestion to demonstrate the use of this technology to process and reduce the size of potted electronics. Processing of these two components was completed by August 1992.

The crushed weapon components were received from Sandia, and the large metal pieces separated to increase processing efficiency. The remaining component materials were loaded separately into glass vessels for processing. The details of each component processed are listed below:

\section{Component №. 2}

As Received inetal Pieces

Process Feed

Sulfuric Used

Nitric Used

Digestion Time

Process Residue

Metal Pieces

Material Shipped

$$
\begin{array}{r}
608 \mathrm{~g} \\
-377 \mathrm{~g} \\
\hline 231 \mathrm{~g} \\
\mathrm{l} \mathrm{L} \\
270 \mathrm{~mL} \\
180 \mathrm{~min} \\
497 \mathrm{~g} \\
+377 \mathrm{~g} \\
\hline 874 \mathrm{~g}
\end{array}
$$

Component No. 3

$$
\begin{array}{r}
999 \mathrm{~g} \\
-807 \mathrm{~g} \\
\hline 192 \mathrm{~g}
\end{array}
$$

$1 \mathrm{~L}$

$150 \mathrm{~mL}$

102 min

$$
\begin{array}{r}
271 \mathrm{~g} \\
+\quad 807 \mathrm{~g} \\
\hline 1,078 \mathrm{~g}
\end{array}
$$

This material was returned to Sandia for further analyses. 


\subsection{FOURTH TEST}

The fourth board, MC2894, No. 5159 , weighed $4,540 \mathrm{~g}$ as received. To make processing more efficient, it was separated into $2,160 \mathrm{~g}$ of aluminum me'cal and $2,380 \mathrm{~g}$ to be digested. Digestion in $2 \mathrm{~L}$ of sulfuric acid?? was started but terminated early to permit the installation of new hoods in the laboratory. Because of the end of the program and fiscal year, the experiment was not completed. The material was successfully solidified with other acid waste from the program.

\subsection{SOLIDIFICATION}

Upon completion of the test work, the remaining acid residue was neutralized and mixed with Portland cement according to standard WHC receipts. After a 30-day cure the three test cylinders ( 6 in. dia $\times 12$ in. high) were crushed and showed fracture strengths of 1,413,1,696, and 2,014 psi. Toxic Leach Characteristic Procedure (TCLP) tests were then conducted on the fragments and the leachate analyzed. The leachate showed no Land-Band metals above regulatory limits, as shown below, so the remaining solids were disposed of as nonhazardous, nonregulated wastes.

\section{Leachate Tests}

$\begin{array}{lcl}\text { Element } & \text { Legal Max (ppm) } & \text { Test Value, max of } 4 \text { (ppm) } \\ \text { Silver, Ag } & 5 & 0.002 \\ \text { Arsenic, As } & 5 & 0.002 \\ \text { Barium, Ba } & 100 & 2.6 \\ \text { Cadmium, Cd } & 1 & 0.9 \\ \text { Chromium, Cr } & 5 & 0.9 \\ \text { Lead, Pb } & 5 & 0.1 \\ \text { Mercury, Hg } & 0.2 & 0.001 \\ \text { Selenium, Se } & 1 & 0.02\end{array}$

\subsection{SUMMARY}

This work showed that the acid digestion process was able to deactivate and process certain electronic components. The solids from the digestion were disposed of as nonhazardous, nonregulated wastes, meeting EPA criteria. The operating time, reagent requirements, and equipment requirements were as expected. Although the volume reduction was usually negative, as theory would predict, the creation of a nonregulated waste product has large advantages. On balance, it would appear that acid digestion is not the ideal technology for the disposal of circuit board waste. 


\section{DISTRIBUTION}

\section{Number of copies}

\section{OFFSITE}

2

Sandia National Laboratory

P.0 Box 5800

Division 6623

Albuquerque, New Mexico 87185

A. A. Lemieux
W. T. Wheel is

ONSITE

5

U.S. Department of EnergyRichland Operations office
D. E. Trader
(5)
K8-50

13

Westinghouse Hanford Company

J. D. Berger

M. D. Crippen (5)

LO-18

J. A. Demiter

L5-31

J. A. Hunter

L5-31

J. C. Womack

L5-31

Central Files

LO-18

Information Release

L8-15

Administration (3)

ᄂ8-07 

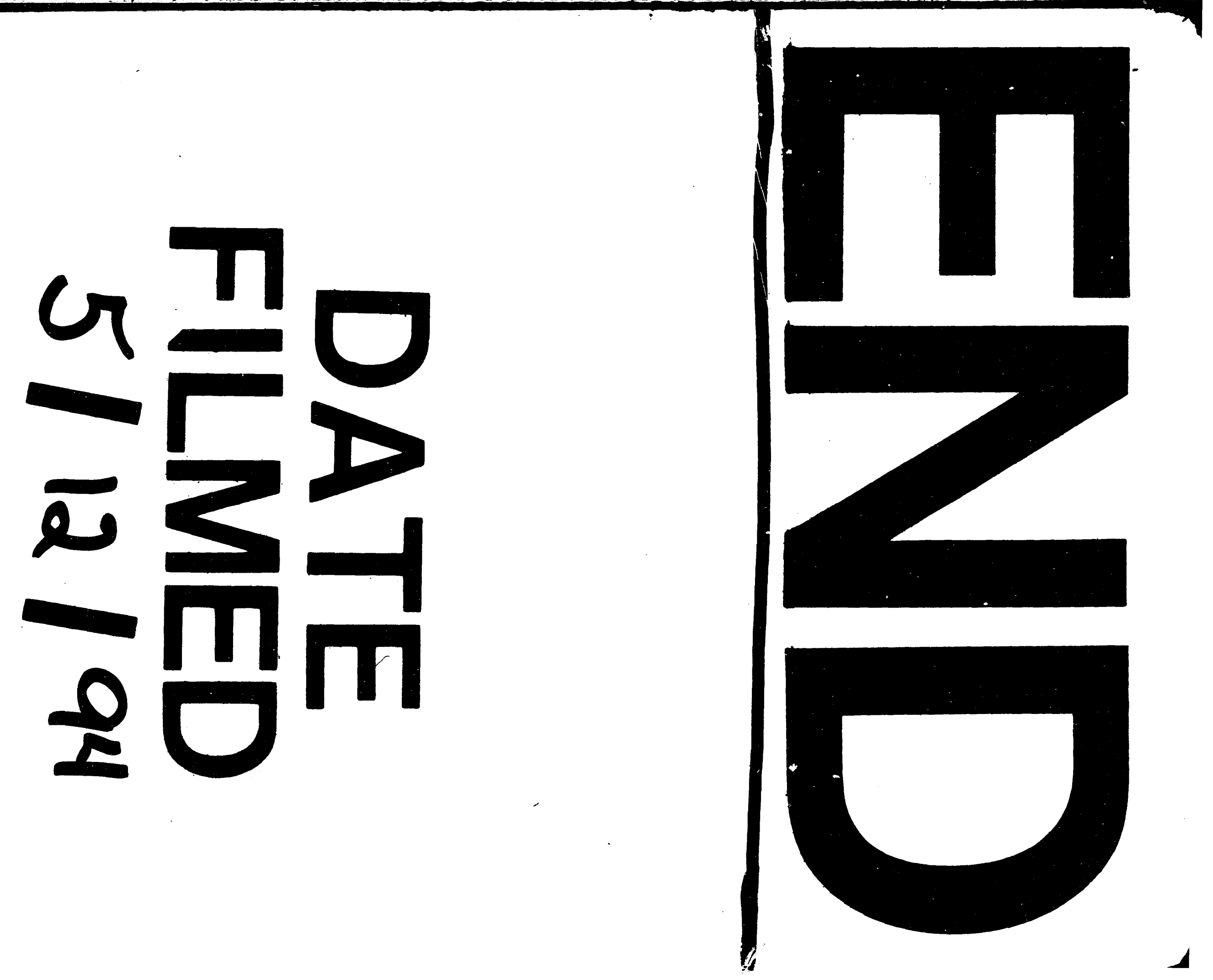
